\title{
Cystic Ovarian Disease and Thyroid Hormones in Dairy Cattle
}

\author{
Hirotada Tsujii* \\ Faculty of Agriculture, Japan \\ *Corresponding author: Hirotada Tsujii, Faculty of Agriculture, Minamiminowa-mura, Nagano 399-4598, Japan
}

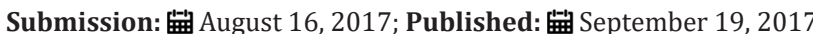

Abbreviations: NEB: Negative Energy Balance; NEFA: Non-Esterified Fatty Acids; Se: Selenium; PUFA: Polyunsaturated Fatty Acids

\section{Mini Review}

Ovarian cysts reduce reproductive efficiency on almost every dairy farm in the World. Cystic ovarian disease in cows is usually seen in the first two months post calving. Ovarian cysts are characterized as structures greater than $2.5 \mathrm{~cm}$ in diameter remaining on an ovary for more than 10 days. Cysts are simply filled with fluid enclosed by membranes like grapes. Since ovarian cysts reduce reproductive efficiency as well as milk production, most dairy farms have very large economic losses.

Though there is no clear consensus on the development of ovarian cysts, it is believed to be associated with many factors, including periparturient stress, aging, nutritional inadequacies, and genetic predisposition [1]. Increased levels of non-esterified fatty acid of follicular fluid are associated with a negative energy balance (NEB). Jorritsma et al. [2] suggested that differences in a NEB or the accumulation of triacylglycerol in the liver of postpartum dairy cows affect fertility performance. The increased lipid content of the follicular fluid is associated with oxidative stress, suboptimal mitochondrial function and reduced developmentally important gene transcripts of oocytes Abe et al. [3]. The association of follicular cysts with abnormal hormone metabolism was also previously assumed Cook et al. [4]. In cows with cystic follicles, progesterone, luteinizing hormone and estradiol- $17 \beta$ concentrations in plasma remain at high levels even around the expected time of ovulation Hatler et al. [5].

Ketone bodies, free fatty acids and glucose have long been used in dairy cattle for energy status changes in the body condition score. In the cystic cows, we found that the concentration of glucose in both follicular fluid and serum is low while the concentration of all the fatty acids in the cystic fluid is markedly increased Tsujii et al. [6]. Moreover, the concentration of fatty acids (especially, palmitic acid and stearic acid) concentration in serum of the cystic cows was higher than the normal estrous cyclic cows. It is reported that these saturated fatty acids were negatively correlated with the oocyte maturation, fertilization, cleavage rate and blastocyst formation. Non-esterified fatty acids (NEFA) may also have an effect on fertility Canfield et al. [7].

There is some evidence for NEFA uptake by the ovary as well as a strong correlation between the concentration of NEFA in plasma and the follicular fluid, which could explain possible harmful effects of NEFA on either granulosa cells or the oocyte [810]. Several studies confirmed the importance of fatty acids for embryo development, but our study indicates that their impaired metabolism and high concentration might lead to the follicular cyst formation. Fatty acids can be regarded as relatively toxic, given the results from studies in sheep Herdt [11]. They showed that an acute increase in serum fatty acid concentration might induce triglycerides accumulation in the liver by elevating cytosolic and microsomal phosphatidate phosphor-hydrolase concentrations, which indicates the toxic potential of fatty acids. We suggest that the vulnerable oocytes should be protected from the too high level of the fatty acids accumulated during the NEB in high-yielding dairy cows.

In the dairy cow, late gestation and early lactation are periods marked by major changes in the sensitivity and responses of tissues to hormones involved in homeostasis, such as insulin and thyroid hormone. Ovarian cysts are linked to an iodine deficiency and therefore iodine supplementation decrease ovarian cysts as well. Cows in postpartum negative energy balance (NEB) respond to decrease the concentrations of $\mathrm{T} 3$ and $\mathrm{T} 4$ and increase the concentration of rT3 [12-15]. Thus, thyroid activity affects the functionality of the reproductive axis and thyroid dysfunction has been associated with ovarian hyperstimulation syndrome and polycystic ovarian syndrome. Thyroid hormones influence all major metabolic pathways. Their most obvious and well-known action is an increase in basal energy expenditure obtained acting on protein, carbohydrate and lipid metabolism. With specific regard to lipid 
metabolism, thyroid hormones affect synthesis, mobilization and degradation of lipids, although degradation is influenced more than synthesis Pucci et al. [16].

A part from the essential trace element iodine, which is the central constituent of thyroid hormones, a second essential trace element, selenium (Se), is required for appropriate thyroid hormone synthesis, activation and metabolism. Selenium is an antioxidant element which is implicated in the activity of the selenoenzymes (glutathione peroxidase, GSH-Px) and in the activation of neutrophils, macrophages and lymphocytes B. In synergy with iodide, it is also involved in the regulation of the thyroid function. The enzyme 5-iodothyronine deiodinase is a seleno-dependent selenoprotein. It is one of the last proteins to be affected in the event of Se deficiency. Selenium supplementation may reduce the incidence of metritis and ovarian cysts during the postpartum period $[17,18]$, reported that adding Se to cows diet significantly increased Se content and percentage of polyunsaturated fatty acids (PUFA) in milk. Several studies have demonstrated the beneficial effects of supplemental selenium or iodide in maintaining thyroid gland and immune competence, and reducing ovarian cysts Mehdi, Dufrasne [19].

Currently, the most effective treatment for cattle with ovarian cyst is gonadotropin-releasing hormone ( $\mathrm{GnRH}$ ), which causes the pituitary to release LH resulting in luteinization of the cyst. Later prostaglandin treatment of luteinizied cyst causes regression of that structure. Pushp et al. [20] reported that the best treatment option was GnRH administration along with potassium iodide feeding for dairy cattle with ovarian cyst. We recommend that selenium or iodide in order to maintain thyroid function should be given to cows before and after parturition of dairy cows for protected from too high of accumulation of fatty acids in the NEB in high-yielding cows [21].

\section{References}

1. Day N (1991) The diagnosis, differentiation and pathogenesis of cystic ovarian disease. Vet Med 86(7): 735-760.

2. Jorritsma R, Jarritsma H, Schukken YH, Wentink GH (2000) Relationships between fatty liver and fertility and some periparturient diseases in commercial Dutch dairy herds. Theriogenology 54(7): 1065-1074.

3. Abe H, Yamashita S, Itoh T, Satoh T, Hoshi H (2002) Accumulation of cytoplasmic lipid droplets in bovine embryos and cryotolerance of embryos developed in different culture systems using serum-free or serum-containing media. Mol Reprod Dev 61(1): 57-66.

4. Cook DL, Parfet JR, Smith CA, Moss GE, Youngquist RS, et al. (1991) Secretory patterns of LH and FSH during developmennt and hypothalamic and hypophysial characteristics following development of steroid induced ovarian follicular cysts in dairy cattle. J Reprod Fertil 91(1): 19-28.
5. Hatler TB, Hayes SH, Laranja da Fonseca LF, Siliva WJ (2003) Relationship between endogenous progesterone and follicular dynamics in lactating dairy cows with ovarian follicular cysts. Biol Reprod 69(1): 218-223.

6. Tsujii H, Miah AG, Salma U, Hidaka N, Yaemori H (2016) Association between Lipid Metabolites and Follicular Cyst Formation in Cattle. Inter J Vet Sci 5(4): 256-261.

7. Canfield RW, Butler WR (1990) Energy balance and pulsatile LH secretion in early postpartum dairy cattle. Domest Anim Endocrinol $7(3): 323-330$.

8. Rabiee AR, Lean IJ, Gooden JM, Miller BG, Scaramuzzi RJ (1997) An evaluation of transovarian uptake of metabolites using arterio-venous difference methods in dairy cattle. Anim Reprod Sci 48(1): 9-25.

9. Comin A, Gerin D, Cappa A, Marchi V, Renaville R, et al. (2002) The effect of an acute energy deficit on the hormone profile of dominant follicles in dairy cows. Theriogenology 58(5): 899-910.

10.Jorritsma R, Wensing T, Kruip TA, Vos PL, Noordhuizen JP (2003) Metabolic changes in early lactation and impaired reproductive performance in dairy cows. Vet Res 34(1):11-26.

11.Herdt TH, Wensing T, Haagsman HP, Van Golde LM, Breukink HJ (1988) Hepatic triacylglycerol synthesis during a period of fatty liver development in sheep. J Anim Sci 66(8): 1997-2013.

12.Pethes GY, Bokori J, Rudas P, Frenyó V L, Fekete S (1985) Thyroxin, triiodothyronine, reverse-triiodothyronine and other physiological characteristics of periparturient cows fed restricted energy. J Dairy Sci 68(5): 1148-1154.

13. Ronge H, Blum J, Clement C, Jans F, Leuenberger H, et al. (1988) Somatomedin $\mathrm{C}$ in dairy cows related to energy and protein supply and to milk production. Anim Prod 47: 165-183.

14. McGuire MA, Vicini JL, Bauman DE, Veenhuizen JJ (1992) Insulin-like growth factors and binding proteins in ruminants and their nutritional regulation. J Anim Sci 70(9): 2901-2910.

15. Yambayamba ES, Price MA, Foxcroft GR (1996) Hormonal status, metabolic changes, and resting metabolic rate in beef heifers undergoing compensatory growth. J Anim Sci 74(1): 57-69.

16. Pucci E, Chiovato L, Pinchera A (2000) Thyroid and lipid metabolism. Int J Obes Relat Metab Disord 24(Suppl 2): 109-112.

17.Wilde D (2006) Influence of macro and micro minerals in the periparturient period on fertility in dairy cattle. Anim Reprod Sci 96: 240249.

18. Ran L, Wu X, Shen X, Zhang K, Ren F, et al. (2010) Effects of selenium form on blood and milk selenium concentrations, milk component and milk fatty acid composition in dairy cows. J Sci Food Agric 90(13): 2214-2219.

19. Mehdi Y, Dufrasne I (2016) Selenium in Cattle: A Review. Molecules 21(4): 545.

20.Pushp MK, Purohit GN, Kumar S (2016) Serum cortisol in dairy cattle with ovarian cyst and the successful treatment of cyst with GnRH plus potassium iodide. Indian J Anim Reprod 37(2): 48-49.

21.Abe H, Yamashita S, Itoh T, Satoh T, Hoshi H (1999) Ultrastructure of bovine embryos a developed from in vitro matured and fertilized oocytes: Comparative morphological evaluation of embryos cultured either in serum-free medium or serum-supplemented medium. Mol Reprod Dev 53(3): 325-335. 